tinct. Discussion of internationalization and higher educational policy occurs in separate silos. As in the European Union and several other jurisdictions, internationalization of higher education has to be addressed within the overall framework of Canadian higher educational policy. Canada needs to engage higher educational policymakers and researchers in the debate and discussion on internationalization and to integrate internationalization into higher education policy.

\section{The International Branch Campus: Models and Trends Line Verbik}

Line Verbik is deputy director of the Observatory on Borderless Higher Education. Address: Woburn House, 20-24 Tavistock Square, London WC1H 9HF, UK. E-mail: I.verbik@obhe.ac.uk. Web site: www.obhe.ac.uk.

The number of international branch campuses has increased significantly over the past decade. Since undertaking its first study of offshore campuses in 2002, the Observatory on Borderless Higher Education has followed developments in this area and recently published a major report, identifying over 80 offshore campuses. The definition of a branch campus is still less than straightforward and lacks global consensus. The term is used in this article to designate an offshore operation of a higher education institution run by the institution or as a joint venture in which the institution is a partner and uses the name of the foreign institution. Upon successful completion of the study program, students are awarded a degree from the foreign institution.

The study shows that the majority of branch campus provision is from North to South. While American institutions continue to dominate this type of overseas delivery, institutions from more countries are engaging in branch campus development. Driving rationales for sending institutions include full control over delivery, prominence in an increasingly competitive transnational education market, greater opportunities for external funding, and changing regulations in some host countries. The sites for branch campus operations are becoming equally diverse, although findings point to a higher level of activity in countries where financial incentives are provided.

\section{MOdel A: Fully Funded by the Institution}

Of the 68 branch campuses for which a funding model has been identified, 37 percent have been established solely through funding from the home institution. However, this approach to offshore operations might become less common as institutions seek more collaborative approaches. The size of the investment required to establish a fully fledged branch campus and the institution's accountability for any losses discourage many institutions from operating on this model. Advantages connected to this approach include the lack of requirements from partners regarding expected investment returns, repayment, and a time frame for the operation to break even.

Of the 16 branch campuses in Model A where a date of opening could be ascertained, 6 were opened after 2000 . However, many of the projects are among the first branch campuses established (e.g., operations in Austria and the Netherlands of the US Webster University in I98I and I983, respectively, and the campus in Mexico of the US Alliant International University in I970) or were established by a forprofit institution (e.g., the operations in Canada and the Netherlands of the University of Phoenix and DeVry University). Both of the latter institutions operate from multiple campuses in their home countries and have raised capital for their continued expansion through stock offerings.

A number of other projects might be best characterized as smaller-scale operations (with limited program offerings and facilities). These include the campuses in London and Singapore of the University of Chicago School of Business, which offer Executive MBA programs, and the facilities in Belgium of Boston University, which focus on business-related diploma and degree programs. The concentration on potentially profitable fields such as business and the limited expenditure of capital on campus facilities may represent attempts to accelerate returns on the institution's investment.

\section{Model B: External Funding}

Thirty-five percent of the branch campuses in the study fall under this model, which can be divided into two main subcategories: (I) recipients of host (central or regional) government funds/support and (2) recipients of external support from private companies or other organizations in the host or home country. In some cases funding comes from more than one external source; for example, a financial contribution from the host government and support from the home government through state-approved loans. Institutions wishing to establish a presence abroad seem to be increasingly opting for funding through Model B. With the exception of three operations, all branch campuses included in this category have been established in the last decade and 70 percent in 2000 or later.

Most branch campuses in receipt of financial or other assistance from the host government have established a presence following an invitation from central or regional authorities. While there are advantages in gaining host government support and funding, an institution needs to evaluate whether the project is in line with its overall mission and institutional goals. In addition, the institution must consider whether it is willing to cover the costs beyond the host country's contribution. Examples of projects in this category include some of the operations established under Singapore's "World Class 
Universities" initiative, including the new campus of Australia's University of New South Wales due to open next year, the branch campus of the US Carnegie Mellon University currently under establishment in the Australian state of South Australia, the campus of the UK University of Nottingham in Ningbo, China, and the campus of Australia's Swinburne University of Technology in Sarawak, Malaysia.

A range of branch campus establishments has been created

The concentration on potentially profitable fields such as business and the limited expenditure of capital on campus facilities may represent attempts to accelerate returns on the institution's investment.

with contributions from external private and public organizations. The opportunities and challenges are almost exactly the opposite of those stated in Model A, with the advantages being the financial contribution and shared risks, and the disadvantages the expectations of the investors in terms of return on investment and their influence on the operation.

Examples of campuses in receipt of investment from public or private organizations include the operation of the University of Nottingham in Malaysia, the US Temple University in Japan, and George Mason University in Ras Al Khaimah, in the United Arab Emirates.

\section{Model C: Facilities Provided}

Model $\mathrm{C}$ is perhaps the latest development within branch campus funding models, but a category that already accounts for 28 percent of the establishments in the study. With the exception of one institution, all developments in this category have been established within the last six years.

Campuses established through Model C make use of facilities provided by a company or a national government often as an enticement to draw foreign providers to the host country. Examples include the Knowledge Village in Dubai, United Arab Emirates and Education City in Qatar. In both cases, a designated zone with academic and student facilities is provided for institutions, which depending on individual arrangements either lease or take over the facilities. The main advantage for institutions operating through this model is the reduction in the start-up funds required. The potential drawbacks include the regulatory environment for the operation (e.g., Knowledge Village operates outside the jurisdiction of the United Arab Emirates and under the guidelines of the company that owns the site) and potential changes in costs outside the institution's control, such as rent increases.

Model C operations are currently found in the economically advanced states of the Gulf. The reasons for this concentration likely include the available public and private funding for such initiatives, lack of capacity and maturity of the domestic higher education system, and developed strategies to change the main foundation for the economy (i.e., to become less dependent on oil). Other countries (e.g., South Korea and Japan) are in the process of establishing special zones for foreign investment, including in education. However, none of them seem to have local investments on the scale of the two examples cited above.

Examples include: five US institutions (e.g., Texas A\&M University and Carnegie Mellon) operating in Qatar's University City and more than I5 institutions (e.g., UK Middlesex and Heriot-Watt Universities, India's Manipal Academy of Higher Education, and Canada's University of New Brunswick) in Knowledge Village.

\section{CONCLUSION}

Institutions appear to be increasingly reluctant or unable to carry the entire costs and risks associated with establishing a campus, leading to a larger number of recent operations being established under Models B and C. While the institutions included in this study are more or less spread evenly across the three models, it is suggested that with time, Models B and C will become more prominent. That being said, further reports of uncertain operating environments (for example, concerns over licenses and rent) could potentially lead to institutions being less willing to operate through a model affording them limited control over certain aspects of the operation.

For further details, please see L. Verbik, and C. Merkley, The International Branch Campus: Models and Trends, Observatory on Borderless Higher Education, 2006, http://www.obhe.ac.uk/products/reports/.

\section{Mainland Chinese Students in Hong Kong and Macau}

\section{MEI LI}

Mei Li is senior lecturer in the Institute of Higher Education at East China Normal University. Address: Institute of Higher Education, School of Educational Science, East China Normal University, Shanghai, 200062, China. E-mail: limeiwang@yahoo.com.

$\mathrm{T}$ The cross-border mobility of students represents a crucial aspect of the internationalization of higher education. The outflow of students from mainland China has long been a striking phenomenon given the imbalance between higher education supply and demand at home. While serving as a major source of foreign students in the United States, the 